\title{
PRODUÇÃO MAIS LIMPA EM EMPRESAS DE GASPAR/SC: UM ESTUDO DE CASO
}

\author{
L. M. DE OLIVEIRA e G. R. PEREIRA* \\ Instituto Federal de Educação, Ciência e Tecnologia de Santa Catarina - Campus Gaspar \\ gracianerp@ifsc.edu.br
}

Submetido 19/12/2016 - Aceito 11/11/2017

DOI: $10.15628 /$ holos.2017.5479

\section{RESUMO}

Ações de produção mais limpa se configuram por medidas, pontuais ou sistematizadas, que venham a eliminar a poluição durante o processo produtivo e não depois dele. Isso significa economia de recursos, minimização de desperdícios, eficiência de equipamentos e processos, e, consequentemente diminuição dos custos. $O$ trabalho procurou diagnosticar práticas de produção mais limpa nas pequenas e médias empresas de Gaspar/SC, bem como as ações dos atores sociais relacionados à gestão ambiental no município, com o intuito de subsidiar futuras intervenções de ensino, pesquisa e extensão. Após aplicação de entrevistas em uma amostra das empresas e instituições do município, verificou-se que há uma falta de comunicação entre as partes. Isto é, para as instituições, existe falta de interesse dos empresários, entretanto, os empresários desconhecem o papel dessas organizações. Além disso, percebeu-se que não existe formação dos empresários em temáticas ambientais e quando existe, é uma formação falha. Contudo, grande parte dos empresários realiza ações de produção mais limpa e têm interesse em participar de capacitações. Nesse sentido, o presente estudo contribui para evidenciar o papel de instituições de ensino e pesquisa, como o IFSC, para trazer capacitação e orientação necessária a fim de consolidar práticas ambientais em todo o país.

PALAVRAS-CHAVE: Produção mais Limpa, Gaspar/SC, Gestão Ambiental Organizacional.

\section{CLEANER PRODUCTION IN GASPAR / SC COMPANIES: A CASE STUDY}

\begin{abstract}
Cleaner production actions are made up of punctual or systematized measures that will eliminate pollution during the productive process and not after it. This means saving resources, minimizing waste, improving equipment and processes efficiency and, consequently, lowering costs. This work sought to diagnose cleaner production practices in small and medium companies in Gaspar / SC, as well as the actions taken by social actors related to environmental management in that municipality, with the purpose to subsidize future teaching, research and extension interventions. After applying surveys in a sample of companies and institutions in the city, it was verified that there is a lack of communication among the parties. That is, for the
\end{abstract}

institutions, there is a lack of interest by the entrepreneurs. However, such entrepreneurs are not aware of the role of those organizations. In addition, it was noticed that there is no training for entrepreneurs in environmental issues and when it exists, it is a failed formation. However, most of the entrepreneurs carry out cleaner production actions and are interested in participating in training. In this sense, the present study contributes to highlight the role of teaching and research institutions, such as the Federal Institute of Santa Catarina (IFSC), to provide the necessary training and guidance in order to consolidate environmental practices throughout the country.

KEYWORDS: Cleaner Production, Gaspar/SC, Organization Environmental Management. 


\section{INTRODUÇÃO}

A inserção da questão ambiental pelo setor produtivo representa, em longo prazo, sua manutenção. Em tempos de escassez de recursos naturais, aumento no custo de fornecimento da energia elétrica, ampliação do consumo sustentável e maior rigidez das leis ambientais, se torna vital que cada organização repense seus processos, objetivando manter-se proativa, eficiente e produtiva.

O setor produtivo gera impactos significativos ao meio ambiente, e tornar menos impactante esta relação é inadiável, pois não existe uma só atividade que não produza algum tipo de impacto negativo. Todo este contexto vem demandando informações sobre ferramentas e estratégias para uma produção mais limpa, em especial às pequenas e médias empresas.

Ações de produção mais limpa se configuram por medidas, pontuais ou sistematizadas, que venham a eliminar a poluição durante o processo produtivo e não depois dele. Isso significa economia de recursos, minimização de desperdícios, eficiência de equipamentos e processos, e, consequentemente diminuição dos custos. A produção mais limpa pode ser realizada por meio de uma diversidade de práticas, incluindo: boas práticas; modificação do processo e/ou equipamento; substituição de materiais; reúso; reciclagem; e mudança nos produtos, serviços, processos e/ou tecnologias (VAN BERKEL, 2007).

Para execução deste trabalho alguns questionamentos iniciais nortearam a pesquisa: Qual o comprometimento ambiental das pequenas e médias empresas do município de Gaspar? Qual o papel de instituições, atores sociais, do município de Gaspar na relação das pequenas e médias empresas e a gestão ambiental? Como o o Instituto Federal de Santa Catarina - IFSC, enquanto instituição de ensino pode auxiliar no fortalecimento ambiental das pequenas e médias empresas de Gaspar? A partir dessas questões o trabalho procurou diagnosticar práticas de produção mais limpa nas pequenas e médias empresas do município, bem como as ações dos atores sociais relacionadas à gestão ambiental no município, com o intuito de subsidiar futuras ações de ensino, pesquisa e extensão pelo IFSC.

\section{REVISÃO BIBLIOGRÁFICA}

\subsection{A necessidade do enfoque ambiental na economia}

Com a Revolução Industrial, o desenvolvimento econômico e os avanços tecnológicos caminharam paralelamente. Neste caminho, grandes centros tornaram-se convidativos aos investimentos empresariais. Todavia, a consequência desse crescimento foi a possibilidade de escassez de recursos naturais à disposição humana (RENSI e SCHENINI, 2006).

Com o mercado demandando mais produtos, tanto em termos quantitativos quanto qualitativos, alguns recursos naturais já dão sinal de exaustão. Segundo Figueiredo (2004) a sociedade atual exige da indústria a utilização de melhores técnicas produtivas que não caminham no mesmo sentido do atendimento de determinados padrões ambientais. Diante disso, é necessário pensar na relação de via dupla entre meio ambiente e indústrias, e, para proteger o meio ambiente e manter os ganhos econômicos na indústria surgem as ferramentas de gestão ambiental. 
Donaire (1995, apud Araújo, 2002) define a gestão ambiental da seguinte forma:

O conjunto de procedimentos bem definidos e adequadamente aplicados que visam reduzir e controlar os impactos introduzidos por um empreendimento sobre o meio ambiente. $O$ ciclo de atuação da gestão ambiental deve cobrir desde a fase de concepção do projeto até a eliminação efetiva dos resíduos gerados pelo empreendimento.

Para Meyer (2000) a gestão ambiental pode ser definida, de maneira esquemática, em quatro partes:

a) objeto - manter o meio ambiente saudável, de forma a atender as necessidades humanas atuais, sem comprometer 0 atendimento das necessidades das gerações futuras;

b) meios - atuar sobre as alterações causadas no meio ambiente pelo uso e/ou descarte dos bens e detritos gerados pelas atividades humanas, a partir de um plano de ação viável técnica e economicamente, com prioridades previamente definidas;

c) instrumentos - monitoramentos, controles, taxações, imposições, subsídios, divulgação, obras e ações mitigadoras, além de treinamento e conscientização;

d) base de atuação - diagnósticos e prognósticos (cenários) ambientais da área de atuação, a partir de estudos e pesquisas dirigidos à busca de soluções para os problemas que forem detectados

A implementação de diversos instrumentos em prol da empresa e do meio ambiente simultaneamente pode ser realizada por meio da gestão ambiental.

\subsection{Produção mais limpa}

Ações de produção mais limpa são ferramentas de gestão ambiental e agem nos processos das empresas, se diferenciando das ações de fim do tubo, aquelas que se preocupam com as saídas dos processos (resíduos, emissões, efluentes). São ações preventivas, por isso são mais efetivas e trazem resultados ambientais e econômicos às empresas, aumentando: a produtividade e eficiência; a competitividade; a saúde e segurança no trabalho; o cuidado com a imagem da empresa junto aos consumidores, fornecedores e órgãos ambientais; a educação ambiental; as perspectivas de atuação no mercado interno e externo; os pontos na obtenção de financiamentos; o incentivo ao contínuo processo de inovação na empresa; a agilidade no licenciamento ambiental; e diminuindo: os custos de produção; os gastos com multas e penalidades previstas na legislação; o consumo de matéria, água e energia; a matéria-prima e outros insumos impactantes para o meio ambiente; os resíduos e emissões; os custos de gerenciamento de resíduos; as taxas de geração de passivos ambientais; os riscos de acidentes ambientais; o tempo de processo e de retrabalho (CNTL, 2015).

Para Rath (2002) a filosofia da produção mais limpa é incorporada dentro de um novo paradigma de sistemas de produção, a abordagem chamada 'Ecologia Industrial'. Este novo paradigma se baseia em princípios ecológicos e salienta a necessidade de compreender o fluxo de energia e materiais através de sistemas industriais, seus efeitos sobre o ambiente e as interrelações entre tecnologias, regulamentos, políticas fiscais e operacionais e as práticas sobre estes 
fluxos. Abordagens industriais ecológicas incorporam a análise de fluxos completos dos processos, a reciclagem de resíduos, ciclo de vida de produtos, desde a concepção inicial do produto e processo até a disposição final, mantendo como objetivo a minimização do impacto ambiental.

O investimento em tecnologias e processos mais limpos é sempre uma decisão importante dos gestores. Algumas barreiras externas podem desencorajar ou impedir as empresas de estabelecerem novos procedimentos, em especial as pequenas e médias empresas, conforme listadas por Gunningham et al. (1997): a complexidade das novas tecnologias, muitas vezes todo o processo produtivo precisa ser mudado; o nível de especificidade tecnológica (algumas novas tecnologias limpas podem ser difíceis de transferir de um usuário para outro); a falta de substâncias alternativas para substituir os componentes perigosos; tecnologias não comprovadas; serviço de má qualidade dos fornecedores; a falta de sistemas integrados de fornecedores (ou seja, soluções completas para a mudança no processo ou produto, e não apenas de um equipamento, por exemplo); o alto custo das soluções de produção mais limpa em relação às tecnologias de fim de tubo, e tecnologias mais limpas que têm preços relativamente mais altos e menor qualidade, porque a escala de produção é menor e com materiais inferiores (inferiores a partir de um ponto de vista não ecológico).

Os mesmos autores concluem que, em contraste, equipamentos tecnológicos de fim de tubo são atrativos, facilmente experimentados, testados, facilmente montados e disponíveis. Os riscos são menores. Para superar essas barreiras há um longo caminho a seguir para que as inovações tecnológicas desenvolvidas sejam de fato apropriadas pelas empresas, em especial as pequenas e médias empresas.

Como o consumo de recursos e a produção de resíduos estão no centro dos processos de fabricação, todas as inovações, eficiências e adaptações que podem ser geradas por meio de uma produção mais limpa também podem beneficiar a posição competitiva da empresa (GUNNINGHAM et al., 1997). Os autores corroboram ainda com outros benefícios de competitividade que podem advir para a indústria: melhorias na produtividade; economia de energia e matérias-primas; redução das necessidades de armazenamento de resíduos e materiais tóxicos; diminuição da responsabilidade; economia em despesas de controle de poluição; uma força de trabalho mais motivada; foco na melhoria contínua; melhoria na saúde e normas de segurança, e um perfil público maior.

Quando uma empresa decide por ações de produção mais limpa ela opta por menos degradação ambiental, por conta dos cuidados em todo o processo produtivo. Como o foco é no processo produtivo, há a necessidade do perfeito entendimento de como as matérias-primas são empregadas e como são gerados resíduos, emissões ou efluentes. Assim, se enfatiza a nãogeração, minimização ou reciclagem de resíduos, trazendo como principais benefícios a redução nos custos de produção, tornando as empresas mais eficientes, competitivas e responsáveis (PEREIRA, 2014).

O Brasil possui uma ampla legislação relacionada ao meio ambiente, como por exemplo, leis federais, as várias resoluções e portarias do CONAMA, as quais se aplicam às empresas micros, pequenas, médias e grandes. As diretrizes legais em vigor estimulam direta ou 
indiretamente à gestão ambiental organizacional, principalmente às relacionadas ao licenciamento ambiental e adequações aos padrões ambientais.

O Estado de Santa Catarina, através da Instrução Normativa 04 - Atividades industriais que orienta o licenciamento ambiental traz a exigência de Projetos de Controle Ambiental, com a seguinte orientação:

Os programas de controle ambiental devem avaliar a possibilidade de intervenções no processo, visando à minimização da geração de efluentes líquidos, efluentes atmosféricos, de resíduos sólidos, de poluição térmica e sonora, bem como a otimização da utilização de recursos ambientais. Simultaneamente a esta providência, o empreendedor deve promover a conscientização, o comprometimento e o treinamento do pessoal da área operacional, no que diz respeito às questões ambientais, com o objetivo de atingir os melhores resultados possíveis com a implementação dos programas de controle ambiental (SANTA CATARINA, 2013).

Percebe-se que existe uma diretriz para as empresas estabelecerem ações mínimas de gerenciamento ambiental.

\subsection{O contexto de Gaspar/SC}

O município de Gaspar localiza-se no Médio Vale do Itajaí em Santa Catarina e possui uma população estimada de 63.826 habitantes (IBGE, 2016). O município apresenta atividades econômicas diversas, com foco na rizicultura, indústria têxtil e comércio, e segundo dados do IBGE havia 3.286 empresas cadastradas em 2012 (considerando todos os tipos e tamanhos). É um município com grande potencial de desenvolvimento por sua localização, perto de rodovias federais e dos Portos de Itajaí e Navegantes.

Esse potencial econômico necessita de orientação no que diz respeito às questões ambientais, para que as empresas possam produzir e se manter em longo prazo. Campos (2012) ressalta que as pequenas e médias empresas representam a maioria dos estabelecimentos do país em várias áreas, como a industrial, a de construção, do comércio e dos serviços, porém com todo esse potencial, a autora constatou que no Estado de Santa Catarina, existem problemas relacionados à produção. A falta de uma produção eficiente gera atrasos na entrega, problemas na linha de montagem e estoques excessivos. Por conseguinte, resulta em perda de materiais, geração de mais resíduos, os quais muitas vezes são lançados no ambiente sem tratamento. Diante disso, nota-se a necessidade de ações que consigam impulsionar mudanças significativas na gestão dessas organizações e para a economia do país.

As pequenas e médias empresas representam 20\% do Produto Interno Bruto (PIB) brasileiro da indústria, são cerca de 9 milhões Micro e Pequenas Empresas (MPE) no País, o que representa mais da metade dos empregos formais. Em relação ao emprego, as MPE representavam $44 \%$ dos empregos formais em serviços, e aproximadamente $70 \%$ dos empregos gerados no comércio (SEBRAE, 2014). Por isso, merecem um olhar diferenciado no que diz respeito à implantação de ações de produção mais limpa. As empresas de grande porte têm condições de implantar um setor específico para a área ambiental ou contratar consultorias externas, já as pequenas e médias empresas, acabam ficando marginais a este processo. 
As pequenas e médias empresas representam, na verdade, o universo do País, em sua diversidade cultural, e dessa forma detêm grande potencial na alavancagem de mudanças favoráveis ao meio ambiente, inclusive transformando as restrições e ameaças ambientais em oportunidades de negócios (SEBRAE, 2004).

Nesse contexto, instituições representativas das pequenas e médias empresas surgem nos municípios para dar o suporte e apoio necessário. Em Gaspar, destacam-se a Associação Empresarial de Gaspar (ACIG), a Associação das Microempresas, Empresas de Pequeno Porte e Empreendedores Individuais (AMPE), e a própria prefeitura do município através da Gerência do Meio Ambiente e Desenvolvimento Sustentável (GEMADS).

Fundada no ano de 1982, a ACIG é uma entidade capaz de gerar instrumentos facilitadores para a classe empresarial, servindo como um ponto de convergência de interesse dos associados, comunidade e gestão pública. A missão da ACIG é descrita da seguinte maneira: "ser a associação empresarial mais atuante e representativa do município, defendendo os interesses de Empresários e Empreendedores dos mais diversos segmentos e classes" (ACIG, 2016).

Instituída em 1985, a AMPE objetiva defender as necessidades dessas empresas, visando um tratamento diferenciado, uma vez que as regras aplicadas para empresas de grande porte não podem ser as mesmas de empresas menores. A consciência ambiental da AMPE é citada na missão da organização, que é: "fomentar o desenvolvimento sustentável e competitividade das organizações empresariais de Gaspar e região" (AMPE, 2016).

Já a Prefeitura de Gaspar possui papel fundamental no diálogo entre as pequenas e médias empresas e o meio ambiente, através da Gerência do Meio Ambiente e Desenvolvimento Sustentável (GEMADS), instituída em 2011. Esse é o órgão responsável pelo licenciamento ambiental e fiscalização das atividades potencialmente poluidoras do município. Dessa forma, a GEMADS executa uma gestão ambiental que seja coerente com a Política Municipal de Meio Ambiente (GASPAR, 2016).

Após identificar os atores sociais do município e suas missões, é importante estabelecer diálogo com essas instituições para verificar o grau de comprometimento com a gestão ambiental e o papel desempenhado junto às empresas.

\section{METODOLOGIA}

\subsection{Aplicação de questionário às empresas}

Para diagnosticar as ações de produção mais limpa nas empresas de Gaspar, bem como, compreender o nível de comprometimento de empresários/colaboradores acerca da gestão ambiental, utilizou-se a aplicação de questionários como instrumento de pesquisa.

Para isso, a prefeitura de Gaspar forneceu a listagem das empresas ativas no município. Esta listagem estava dividida de acordo com a Classificação Nacional de Atividades Econômicas (CNAE). Assim, aplicou-se um questionário adaptado de ABRAPP (2013) e CETESB/PNUMA (2004) a uma amostra qualitativa de 15 empresas. Os entrevistados estavam ligados à direção das empresas. A extensão territorial de Gaspar, a grande quantidade de indústrias e o tempo de realização do trabalho foram fatores limitantes da pesquisa. 
3.2 Entrevista semi-estruturada com os atores sociais do município de Gaspar relacionados à gestão ambiental

Para dialogar com os dados obtidos na aplicação dos questionários com as empresas (3.1), realizou-se uma entrevista semi-estruturada junto aos atores sociais identificados no município: ACIG, AMPE e GEMADS, com questões sobre gestão ambiental, produção mais limpa, atividades desenvolvidas junto às empresas.

\section{RESULTADOS E DISCUSSÕES}

\subsection{Aplicação de questionário às empresas}

Das quinze empresas do município de Gaspar que responderam ao questionário, 53,3\% atuam no setor têxtil, $26,7 \%$ no setor de química e plástico, 6,7\% no setor moveleiro, 6,7\% no setor de comunicação visual e 6,7\% no setor de construção civil. Em relação ao cargo de atuação dos entrevistados, houve grande variação, conforme ilustra a Tabela 1.

\begin{tabular}{c|c}
\hline Cargo & \% \\
\hline Gerente de produção & 20 \\
\hline Proprietário da empresa & 20 \\
\hline Analista de Recursos Humanos & 13,3 \\
\hline Comprador & 13,3 \\
\hline Administrador & 6,7 \\
\hline Diretor da empresa & 6,7 \\
\hline Gerente de qualidade & 6,7 \\
\hline Técnico de produção e processos & 6,7 \\
\hline Sem resposta & 6,7 \\
\hline
\end{tabular}

Tabela 1: Cargo de atuação dos entrevistados Fonte: Autores.

Sabendo do perfil das empresas e dos funcionários entrevistados, a primeira questão abordada no questionário indagava aos respondentes sobre a existência de estrutura específica para gerir as questões ambientais, tais como comissões, comitês ou diretorias.

Os resultados mostraram que $73,3 \%$ das empresas não possuem e $26,7 \%$ afirmam que a empresa possui alguma estrutura para gestão ambiental. Dentre estes, as citações apresentadas foram: "a engenheira ambiental [da empresa] é quem presta consultoria" e "de acordo com a necessidade a comissão é acionada para reunião".

Destarte, é necessário refletir sobre como os membros da empresa veem as formas de estruturar uma comissão ou comitê ambiental e quais seriam as formas de integrar uma equipe para gerir a temática ambiental dentro das empresas. Llerena (1996, apud Corazza, 2003) cita uma pesquisa com 108 empresas (cujo porte não foi citado): 57 alemãs e 51 britânicas e constatou as seguintes características estruturais:

- $70 \%$ das empresas designaram um responsável ambiental dispondo de um departamento (35\%) e de um orçamento específico (43\%).

- As empresas britânicas se caracterizam ainda pela criação de um comitê especializado em questões ambientais $(72,5 \%)$ e de instrumentos de controle interno específicos $(80,4 \%)$. 
- Critérios ambientais são levados em conta nos projetos de investimento $(68,5 \%)$ e no desenvolvimento de novos produtos $(80 \%)$.

A questão seguinte indagou se a temática de gestão ambiental e/ou produção mais limpa estão inseridas nas diretrizes da empresa, isto é, se elas estão incluídas na visão, valores e/ou missão. Constatou-se que $40 \%$ das empresas incluem a temática, $46,7 \%$ não e 13,3\% não souberam responder.

Posteriormente, o entrevistado foi questionado se algum membro da empresa já participou de alguma capacitação ou palestra sobre as questões ambientais. 53,3\% afirmam que não, $40 \%$ que sim e 6,7\% não souberam responder.

Confrontando os dados dessas três questões, é necessário questionar de que forma as ferramentas de gestão ambiental são colocadas em prática dentro dessas empresas. Uma vez que, $73,3 \%$ das empresas não possuem estruturas que discutam o tema e 53,3\% não possui algum membro com capacitação na temática, porém $40 \%$ delas se comprometem com a temática em suas diretrizes.

Aprofundando os eixos da gestão ambiental, a sexta pergunta fez menção ao uso eficiente da água. Nesta, $60 \%$ dos entrevistados afirmam que a empresa trata do uso eficiente da água, $20 \%$ não e, em $20 \%$ dos casos, a água não fazia parte do processo produtivo da empresa. A Figura 1 demonstra as maneiras de cada empresa utilizar a água de forma eficiente.

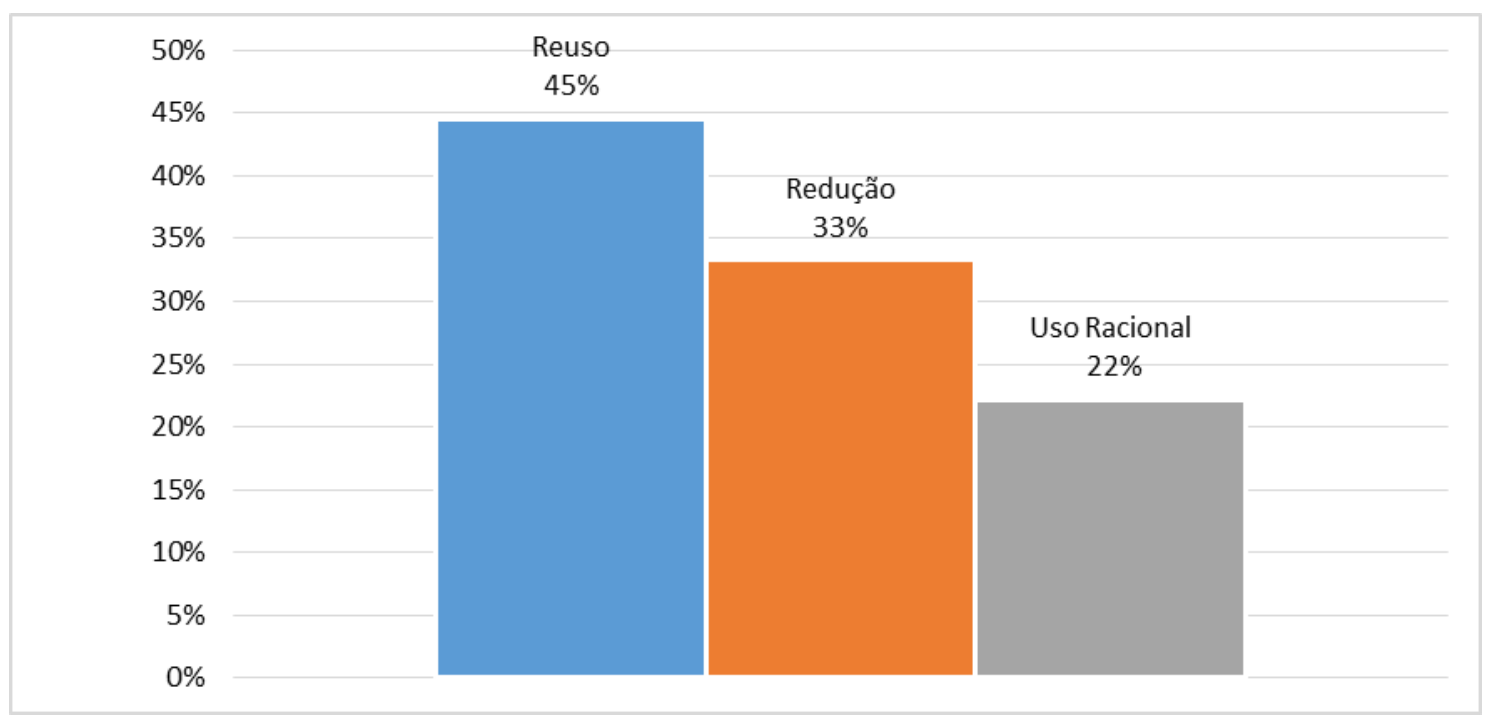

Figura 1: Maneiras eficientes de utilizar a água citadas pelas empresas. Fonte: Autores.

Em relação ao uso eficiente de energia, proposta da questão seguinte, $46,7 \%$ das empresas buscam utilizar de forma mais eficiente a energia; $56,6 \%$ diz que não; $6,7 \%$ não souberam responder; e, em $20 \%$ dos casos a energia não fazia parte do processo produtivo da empresa. Entre as justificativas dadas pelos entrevistados estão: o uso de subestações e geradores de energia, lâmpadas mais eficientes e uso racional.

A oitava questão verificou se as empresas buscam minimizar os resíduos sólidos oriundos de seu processo produtivo. Assim, $80 \%$ das empresas afirmam minimizar o uso de resíduos 
sólidos e o restante, $20 \%$, não. Pressupõe-se que a preocupação na gestão com esse tipo resíduo seja maior devido à ampla legislação e fiscalização de resíduos sólidos no país.

Posteriormente, os entrevistados foram abordados sobre como o resíduo sólido é gerenciado na empresa, isto é, se existem medidas sistematizadas para reduzir, tratar, armazenar e/ou dispor os resíduos. Nesse momento, 46,7\% dos entrevistados não sabiam responder ou assinalaram a opção "não se aplica". Isto demonstra uma falta de conhecimento e entendimento do aspecto por parte dos entrevistados, uma vez que todas as empresas geram resíduos sólidos e afirmaram que minimizam os resíduos. Também se pode perceber que a Política Nacional de Resíduos Sólidos, em vigor há mais de cinco anos, ainda não é conhecida e implementada pelas empresas.

Do restante das empresas (53,3\%), 87,5\% faz a coleta seletiva desses materiais ou vendem o material com valor comercial e $12,5 \%$ contratam empresas licenciadas para descartar corretamente os materiais.

Em relação ao tratamento de poluentes atmosféricos, a parte majoritária das empresas afirma que esse tipo de poluente não é gerado durante seu processo produtivo (53,3\%). Entre as empresas que emitem poluentes atmosféricos, apenas 13,3\% afirmam tratar sua emissão e $26,7 \%$ não fazem nenhum tipo de tratamento. O restante $(6,7 \%)$ não soube responder.

O tratamento de resíduos perigosos foi o foco da décima pergunta. Aproximadamente $53,3 \%$ das empresas afirmam tratar desses resíduos, descartando corretamente através de serviços prestados por outras empresas. $26,7 \%$ não souberam responder e $20 \%$ das empresas afirmam que esse tipo de material não é gerado no processo produtivo.

Os efluentes oriundos das atividades das empresas, tantos os industriais quanto os esgotos, são tratados e destinados corretamente em $66,7 \%$ dos casos. Apenas $6,7 \%$ não faz o tratamento e o restante $(26,6 \%)$ assinalaram a opção "não se aplica".

Quando questionadas sobre quais atividades realizam para minimizar o odor e o ruído gerados durante o processo produtivo, $20 \%$ das empresas não realizam nenhuma ação para minimização, 6,7\% não sabiam responder e $40 \%$ das empresas afirmam não produzir odor ou ruído. Entre os 33,3\% das empresas que realizam ações de minimização, destacam-se algumas citações:

\footnotetext{
"Respeitamos a legislação, produzindo ruído e odor dentro dos limites de horário".

"Realizamos a manutenção das máquinas, sempre que necessário, para não gerar tanto ruído".

"Sempre buscamos minimizar, atualmente nossos impactos são pequenos".

"Utilizamos aparelhos de acústica".
}

Comparando todos esses aspectos (água, energia, resíduos sólidos, poluentes atmosféricos, resíduos perigosos, efluentes, odores e ou ruídos) é possível visualizar em qual ponto a amostra de empresas realiza mais ações em termos de gestão ambiental. A Figura 2 apresenta esse resumo. 


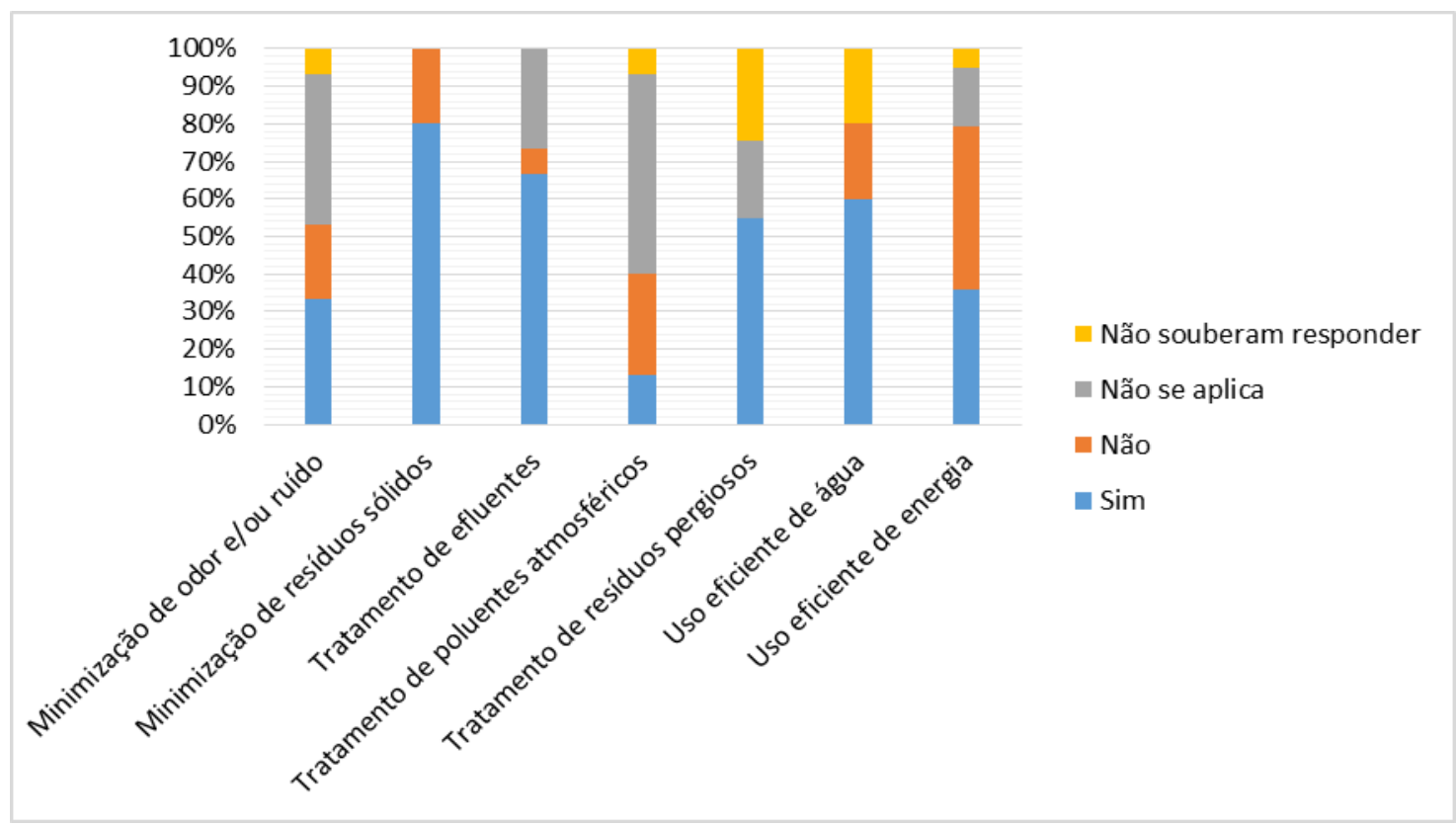

Figura 2: Realização de ações de gestão ambiental por aspecto. Fonte: Autores.

Observa-se que a minimização de resíduos sólidos, o tratamento de efluentes e o uso eficiente da água são aspectos onde os empresários apresentam maior preocupação. Além disso, cinco dos sete aspectos apresentam entrevistados sem conhecimento do assunto, assinalando a opção "não sei responder".

Quando questionados sobre os riscos que a empresa oferece a vizinhança, tais como vazamentos, incêndios ou explosão, $46,7 \%$ das empresas reconhecem esse risco. Dentre as medidas seguranças citadas pelos entrevistados destacam-se algumas respostas:

"Possuímos extintor de incêndio e somos orientados sobre seu uso pela empresa que fornece o produto".

"Estamos adequando a fiação de eletricidade à NR10".

"Possuímos uma Comissão de Interna de Prevenção de Acidentes (CIPA)".

"Nossos riscos são monitorados de forma muito séria, possuímos planos de emergência e brigada de incêndio".

"Realizamos limpezas periódicas nos maquinários e manutenção preventiva".

"Enclausuramos os inflamáveis de acordo com as normas do corpo de bombeiros".

"Possuímos uma bacia de contenção para evitar contaminação por vazamentos".

Quando questionados se as empresas investem no uso de ferramentas de gestão ambiental, como selos verdes, certificação ambiental, entre outros, apenas 13,3\% afirmam realizar investimentos desse tipo. $66,7 \%$ não realizam e os outros $20 \%$ assinalaram a opção não se aplica ou não souberam responder. Esse dado confronta-se novamente com a alta porcentagem (40\%) de empresas que incluem a temática ambiental em suas diretrizes, porém a porcentagem de empresas que investem em prol disso é muito inferior.

Em seguida, os entrevistados foram questionados sobre o valor gasto em iniciativas ambientais no ano anterior, $80 \%$ não souberam responder e dentre a parcela que respondeu, obtiveram-se respostas incipientes. Apesar disso, $80 \%$ das empresas acreditam que as práticas de 
produção mais limpa podem diminuir os gastos da empresa. A Figura 3 demonstra a forma e a proporção como os entrevistados entendem que a $\mathrm{P}+\mathrm{L}$ pode diminuir os gastos na empresa.

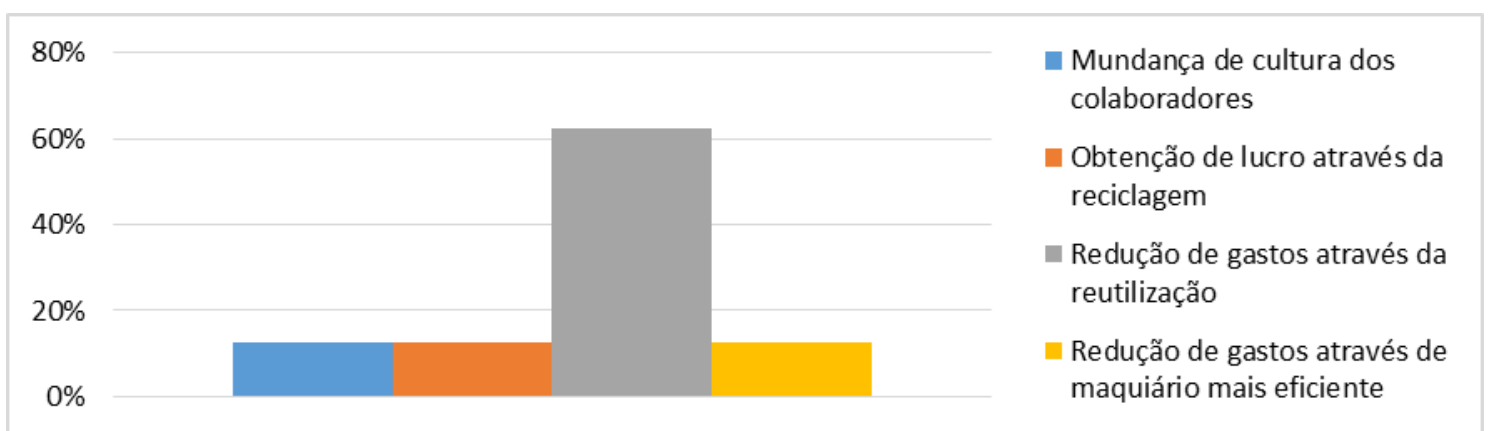

Figura 3: Diminuição de gastos através da $P+L$ segundo os entrevistados.

Fonte: Autores.

Em tese, há consciência dos empresários sobre os benefícios da gestão ambiental, contudo, as empresas têm investido pouco em ações ambientais.

A questão seguinte indagou se a empresa, ao procurar um banco para financiamentos, é exigida a realizar práticas ambientais. $46,7 \%$ dos entrevistados dizem que sim, que são exigidas documentações da empresa (emitidas pela Fundação de Meio Ambiente de SC - FATMA, GEMADS, por exemplo). Outros 33,3\% dizem que não e $20 \%$ não soube responder.

A fim de diagnosticar a consciência ambiental dos consumidores dessas empresas, a pergunta posterior abordou se seus consumidores exigem práticas de produção limpa ou gestão ambiental na hora de comprar algum produto. Apenas $26,6 \%$ afirmaram que sim, $66,7 \%$ que não e 6,7\% não souberam responder.

Para verificar o posicionamento das entidades governamentais, os entrevistados foram questionados se já receberam algum investimento do governo para promover ações no âmbito ambiental. Apenas 6,7\% afirmaram que sim. Em contrapartida, os entrevistados citam algum apoio de atores sociais da região (ACIG, AMPE, IEL, FIESC, SEBRAE, SENAC, SENAI, SESI). Este apoio, não é financeiro, mas em forma de capacitações e treinamentos. A Figura 4 compara a visão dos entrevistados entre o estímulo por parte do governo e o os atores sociais para ações ambientais.

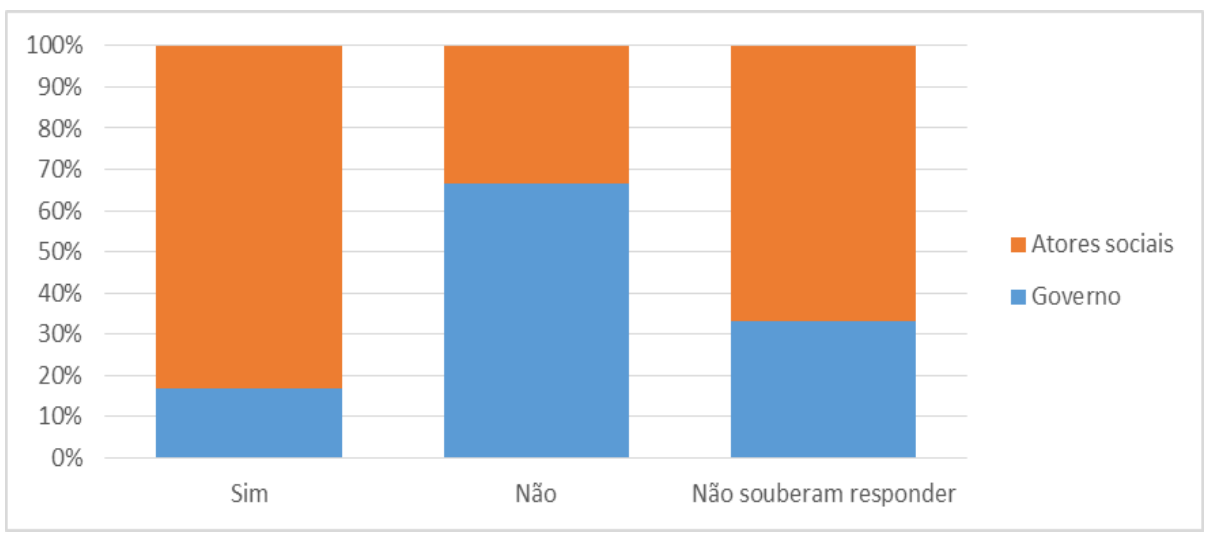

Figura 4: Apoio do governo e dos atores sociais para a promoção da $P+L$, segundo os entrevistados. Fonte: Autores. 
Posteriormente, os entrevistados foram questionados sobre a parte legal atrelada ao meio ambiente. Nesse sentido, verificou-se que $60 \%$ das empresas possuem licenciamento ambiental, 13,3\% não possui licenciamento ambiental e $26,7 \%$ não soube responder. Essa última parcela representa uma fragilidade na comunicação dentro das empresas no diz respeito ao meio ambiente, uma vez que o entrevistado não soube responder se a empresa está de acordo com a legislação ambiental.

Dentre as empresas que possuem o licenciamento, 53,3\% delas dizem que foi necessário adotar algumas práticas para se adequar ao licenciamento ambiental, $40 \%$ dizem que não foi adotada nenhuma prática e $6,7 \%$ não soube responder.

O último ponto da aplicação dos questionários buscou escutar os entrevistados sobre as barreiras e as recomendações identificadas no momento de efetivar ações no âmbito ambiental. A Figura 5 demonstra as barreiras identificadas e em qual proporção elas são citadas.

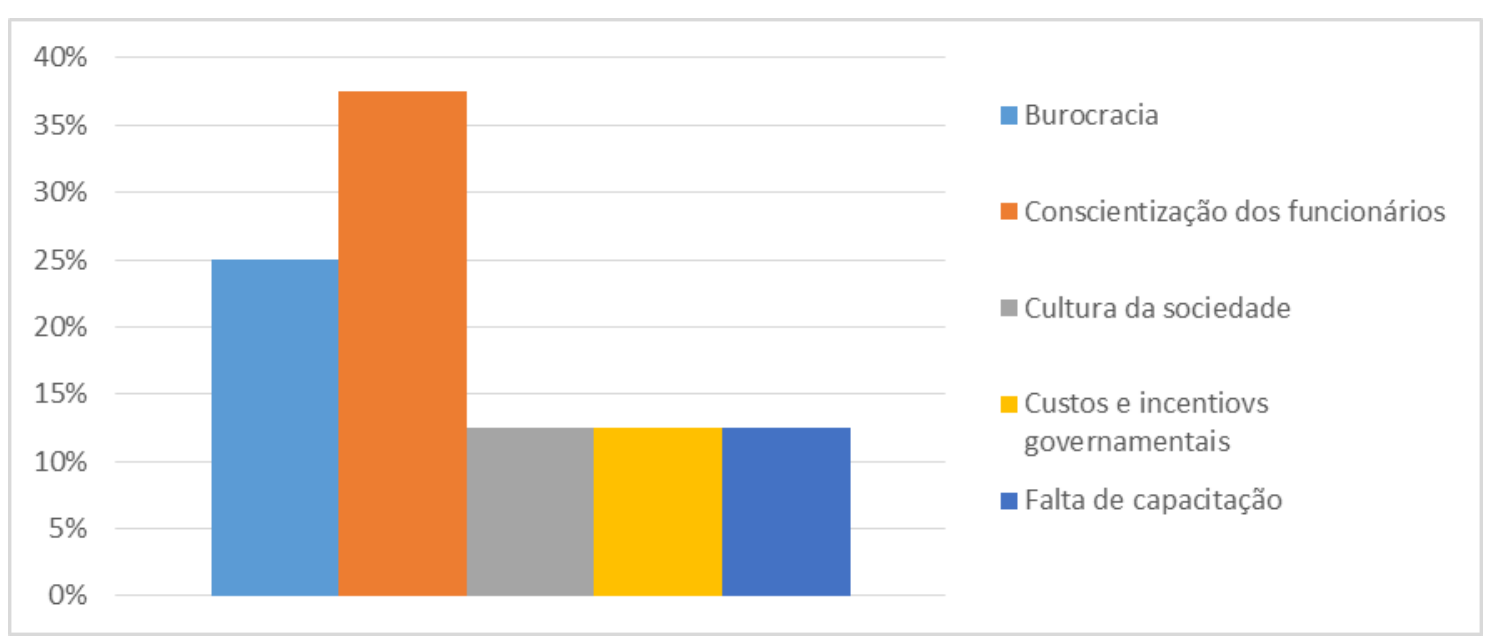

Figura 5: Barreiras para a efetivação da gestão ambiental segundo os entrevistados. Fonte: Autores.

Para finalizar, $86,7 \%$ das empresas demonstram interesse em participar de alguma capacitação caso o IFSC ofereça.

\subsection{Entrevista semi-estruturada com os atores sociais}

A entrevista semi-estruturada foi feita com três atores sociais do município e se deu pela fala do representante maior em nível hierárquico de cada instituição. Por se tratar de uma entrevista semi-estruturada, as perguntas em cada organização sofreram alterações devido ao rumo que os entrevistados deram à conversa. A seguir, são destacados alguns aspectos significativos das conversas.

$\mathrm{Na}$ visão da $\mathrm{AClG}$, existe uma cobrança dos órgãos governamentais com relação aos instrumentos de comando e controle e pouca ação de fiscalização. Também afirmam não receber incentivos do governo para formações na temática ambiental. O órgão afirma já ter realizado algumas ações pontuais para promoção da gestão ambiental, e reconhecem que essas deveriam ser permanentes, já que os empresários são bastante individualistas e têm dificuldade de pensar coletivamente. A associação não possui núcleo que discuta a temática ambiental. Também 
informaram ter poucas empresas associadas e que, em virtude da atual conjuntura econômica do país acabaram perdendo mais associados.

A AMPE afirma não ter diretrizes ambientais consolidadas. Realiza algumas ações pontuais, como plantio de árvores para neutralização do carbono gerado pelas atividades da associação. Em outros momentos discutiram o impacto ambiental de empresas que desejavam se instalar em Gaspar. Também afirmaram não receber nenhum apoio governamental para ações ambientais. Veem como ponto positivo a participação, com representantes, em vários colegiados (conselhos municipais, por exemplo) da sociedade, o que pode ser um potencial transformador. Para o presidente, a verticalização da produção no município é um entrave, pois existem empresas irregulares (facções principalmente), e como não há fiscalização as empresas não evoluem profissionalmente.

Para o órgão ambiental do município, a GEMADS tem como principal função e relacionamento com as empresas, o licenciamento ambiental, principalmente no que diz respeito ao gerenciamento dos resíduos sólidos industriais. Com as informações das empresas o órgão pode orientar a empresa na busca de meios para redução da geração de resíduos nos processos. Segundo o órgão, essas orientações são tão eficazes que chegam a diminuir entre 20 a $40 \%$ os resíduos e/ou efluentes gerados. Houve o seguinte exemplo:

Uma estamparia que gera em torno de $30.000 \mathrm{~L}$ de efluente na lavação de quadros, alterando a pressão da água de saída da lavação dos quadros consegue ter uma ótima redução do seu efluente e consumir menos água. A empresa passa a ter dois ganhos, menor consumo de água e menor custo para o tratamento do efluente. $O$ meio ambiente é beneficiado ${ }^{1}$.

Há percepção do órgão que nos últimos anos as empresas conseguem relacionar a proteção do meio ambiente com menor custo e qualidade para os funcionários e aproveitam isso como marketing ambiental.

Em comum os atores entendem a necessidade de oferta de cursos e capacitações aos empresários do município. Há falta de articulação entre esses atores no que diz respeito à gestão ambiental ou produção mais limpa. Também se percebe que o discurso dos empresários é coerente com essas entrevistas, há pouca influência dos atores na promoção de ações de produção mais limpa.

\section{CONSIDERAÇÕES FINAIS}

A presente pesquisa diagnosticou o cenário da gestão ambiental em Gaspar e buscou traçar um diálogo entre os empresários e os atores sociais do município. Verificou-se que há uma falta de comunicação entre as partes. Isto é, para os atores sociais existe falta de interesse dos empresários, entretanto, os empresários pouco sabem do papel que essas organizações exercem e qual é sua função no município.

1 Comunicação pessoal, Gerência de Meio Ambiente de Desenvolvimento Sustentável de Gaspar, Novembro de 2015 . 
As entrevistas com os empresários apontaram que praticamente $40 \%$ dos entrevistados têm diretrizes ambientais, porém mais de $70 \%$ não têm estruturas organizacionais para gerir ações de produção mais limpa. Por conta principalmente dos instrumentos de comando e controle, as empresas realizam ações de produção mais limpa, com destaque para o gerenciamento de resíduos sólidos, de resíduos perigosos, e uso eficiente de água e energia.

Além disso, o questionário aplicado as empresas, de forma geral, demonstrou que não existe formação dos empresários em temáticas ambientais e quando existe, é uma formação falha. Contudo, grande parte dos empresários demonstra interesse em participar de capacitações. Nesse sentido, o presente estudo contribui para evidenciar o papel de instituições de ensino e pesquisa, como o IFSC, para trazer capacitação e orientação necessária a fim de legitimar práticas ambientais em todo o país.

Sugere-se continuidade do estudo, como também a possibilidade de oferta de cursos e/ou treinamentos para empresários pelo IFSC em parceria com os atores sociais do município e região.

\section{REFERÊNCIAS}

ABRAPP. Questionário de desempenho ambiental, social e de governança para os Fundos de Pensão. 2013. Disponível em: <http://www.abrapp.org.br/SitePages/

RelatorioSocial2013.aspx>. Acesso: 09 dez. 2016.

ACIG. A Associação. Disponível em: < http://www.acigweb.com.br/a-associacao.html >. Acesso: 09 dez. 2016.

AMPE. A AMPE Gaspar. Disponível em: <http://www.ampegaspar.com.br/ampe/a-ampegaspar>. Acesso em: 09 dez. 2016.

ARAUJO, Alexandre Feller. A aplicação da metodologia de produção mais limpa: estudo em uma empresa do setor de Construção Civil. 2002. 120 f. Dissertação (Mestrado em Engenharia de Produção) - Programa de Pós-Graduação em Engenharia de Produção, Universidade Federal de Santa Catarina, Florianópolis, 2002.

CAMPOS, Lucila M. S. Environmental management systems (SEM) for small companies: a study in Southern Brazil. Journal of Cleaner Production. 32, 141-148. 2012.

CNTL. SENAI. Histórico. Disponível em: <http://wwwapp.sistemafiergs.org.br/portal/page/portal/sfiergs_senai_uos/senairs_uo697/ CNTL\%2OSENAI\%20-\%20HIST\%D3RICO_0.pdf>. Acesso em 17 abr. 2015.

CORAZZA, Rosana Icassatti. Gestão ambiental e mudanças da estrutura organizacional. Revista de Administração de Empresas (RAE-eletrônica) (2003): 1-23.

FIGUEIREDO, Veruschka Franca de. Produção mais limpa nas pequenas e micro empresas: elementos inibidores. XXIV Encontro Nac. de Eng. de Produção-Florianópolis, 2004. Disponível em: <http://www.abepro.org.br/biblioteca/enegep2004_enegep1002_1745.pdf>. Acesso 14 ago 2015.

GASPAR. Gerência do Meio Ambiente e Desenvolvimento Sustentável. Disponível em <http://www.gaspar.sc.gov.br/estruturaorganizacional/hotsite/index/codHotsite/1229/contra ste/ativar>. Acesso: 09 dez. 2016. 
GUNNINGHAM, Neil; SINCLAIR, Darren; BURRIT, Patricia. Acel final report: barriers and motivators to the adoption of cleaner production practices. Published by the Australian Centre for Environmental Law. The Australian National University. Canberra, July 1997. Disponível em < http://www.unep.fr/shared/publications/other/WEBx0072xPA/Manual _cdrom/CPlinks/pdfs/barriers.pdf>. Acesso em: 27 Abr 2015.

IBGE. Gaspar. Disponível em: <http://cidades.ibge.gov.br/xtras/perfil.php?lang=\&codmun= 420590\&search=santa-catarina |gaspar|infograficos:-informacoes-completas $>$. Acesso em 09 dez. de 2016.

CETESB/PNUMA. A produção mais limpa e o consumo sustentável na América Latina e Caribe. Relatório sobre produção mais limpa e consumo sustentável na América Latina e Caribe. São Paulo: CETESB/PNUMA, 2004.2 Disponível em <http://www.cqgp.sp.gov.br/gt_licitacoes/publicacoes/AProducaoMaisLimpaeoConsumoSust entavelNaALeC.pdf >. Acesso: 09 dez. 2016.

MEYER, Murilo Machado. Gestão Ambiental no Setor Mineral: um estudo de caso. Florianópolis, 2000. 193f. Dissertação (Mestrado em Engenharia de Produção) - Programa de Pósgraduação em Engenharia de Produção, UFSC, 2000.

PEREIRA, Graciane Regina. Subsídios para implantação da Produção mais Limpa no Brasil [tese] /Graciane Regina Pereira; orientador: Fernando Soares Pinto Sant'Anna. UFSC - Florianópolis, SC, 2014.

RATH, Amitav. Cleaner Production and Cleaner Energy: Towards Increased Action in the Hemisphere. For the First Hemispheric Meeting of Ministers and High Authorities on Science and Technology. Organized by the OAS. Policy Research International Inc. Ottawa, Canadá, 2002.

em: <http://portal.oas.org/Portals/7/Ciencia_Tecnologia/Clean_Prodn_Clean_Energy_3.1\%5B1\%5 D.pdf>. Acesso em: 16 Abr. 2015.

RENSI, Francini; SCHENINI, Pedro Carlos. Produção mais limpa. Revista de Ciências da Administração, v. 8 , n. 16, p. 293-315, 2006. Disponível em: <https://periodicos.ufsc.br/index.php/adm/article/viewArticle/1728>. Com acesso 11 ago 2015.

. Participação das Micro e Pequenas Empresas na Economia Brasileira. 2014. Disponível em: <https://www.sebrae.com.br/Sebrae/Portal\%20Sebrae/Estudos\%20e\%20Pesquisas/

Participacao\%20das\%20micro\%20e\%20pequenas\%20empresas.pdf>. Acesso em: 09 dez. 2016.

SEBRAE. A questão ambiental e as empresas. Brasília: Sebrae, 4a edição, 2004. Disponível em:< https://rmdaveiga.files.wordpress.com/2011/01/questao-ambiental.pdf >. Acesso em: 09 dez. 2016.

SANTA CATARINA. FATMA. Instrução Normativa 04 - Atividades industriais, atualizada em 28/05/2014. Disponível em: <http://www.fatma.sc.gov.br/images/stories/Instrucao\%20Normativa/IN \%2004/in_04.pdf>. Acesso em: 19 dez. 2016.

VAN BERKEL, Rene. Cleaner production and eco-efficiency initiatives in western Australia 19962004. Journal of Cleaner Production, 15 (2007), 741-755. 